\title{
Identification of cell-surface markers for detecting breast cancer cells in ovarian tissue
}

\author{
Inge T. A. Peters ${ }^{1}$ - Carina G. J. M. Hilders ${ }^{2}$ - Cornelis F. M. Sier ${ }^{3}$ - Alexander L. Vahrmeijer ${ }^{3}$. \\ Vincent T. H. B. M. Smit ${ }^{4}$ J. Baptist Trimbos ${ }^{1} \cdot$ Peter J. K. Kuppen $^{3}$
}

Received: 14 May 2015/Accepted: 3 February 2016/Published online: 5 March 2016

(c) The Author(s) 2016. This article is published with open access at Springerlink.com

\begin{abstract}
Purpose The safety of ovarian tissue autotransplantation in oncology patients cannot be ensured, as current tumordetection methods compromise the ovarian tissue viability. Although non-destructive methods (for instance near-infrared fluorescence imaging) can discriminate malignant from healthy tissues while leaving the examined tissues unaffected, they require specific cell-surface tumor markers. We determined which tumor markers are suitable targets for tumor-specific imaging to exclude the presence of breast cancer cells in ovarian tissue.

Methods Immunohistochemistry was performed on formalin-fixed, paraffin-embedded specimens of ten ovaries from premenopausal patients. Additionally, we screened a tissue microarray containing tumor tissue cores from 24 breast cancer patients being eligible for ovarian tissue cryopreservation. The following cell-surface tumor markers were tested: E-cadherin, EMA (epithelial membrane antigen), Her2/neu (human epidermal growth factor receptor type 2), $\alpha \mathrm{v} \beta 6$ integrin, EpCAM (epithelial cell adhesion molecule), CEA (carcinoembryonic antigen), FR-
\end{abstract}

Peter J. K. Kuppen

p.j.k.kuppen@lumc.nl

Inge T. A. Peters

i.t.a.peters@lumc.nl

1 Department of Gynecology, Leiden University Medical Center, Leiden, The Netherlands

2 Department of Gynecology, Reinier de Graaf Hospital, Delft, The Netherlands

3 Department of Surgery, Leiden University Medical Center, Leiden, The Netherlands

4 Department of Pathology, Leiden University Medical Center, Leiden, The Netherlands $\alpha$ (folate receptor-alpha), and uPAR (urokinase-type plasminogen activator receptor). For each tumor, the percentage of positive breast tumor cells was measured.

Results None of the ten ovaries were positive for any of the markers tested. However, all markers (except CEA and uPAR) were present on epithelial cells of inclusion cysts. E-cadherin was present in the majority of breast tumors: $\geq 90 \%$ of tumor cells were positive for E-cadherin in 17 out of 24 tumors, and $100 \%$ of tumor cells were positive in 5 out of 24 tumors.

Conclusions Of the markers tested, E-cadherin is the most suitable marker for a tumor-specific probe in ovarian tissue. Methods are required to distinguish inclusion cysts from breast tumor cells.

Keywords Autotransplantation - Ovarian tissue $\cdot$ Breast cancer $\cdot$ Tumor markers $\cdot$ Fertility preservation

\section{Introduction}

Premature ovarian failure is the most common long-term major adverse effect in premenopausal women following chemotherapy [1]. Because loss of fertility can significantly decrease quality of life [2], considerable effort has been devoted to offer these patients options for preserving their fertility. These options currently include cryopreservation of embryos and/or oocytes. Besides, autotransplantation of pretreatment cryopreserved ovarian tissue is becoming more prevalent and is considered predominantly feasible for both prepubescent girls and women who cannot postpone adjuvant therapy [3-5].

Although autotransplantation of frozen-thawed ovarian tissue has improved greatly in recent years [6,7], its safety is questionable for certain types of cancer at risk of ovarian 
involvement, as it remains uncertain whether the transplanted cortical ovarian strips contain metastatic cells. This uncertainty arises from the highly damaging effects of currently available tumor-detection methods (e.g., PCR, immunohistochemistry) on tissue viability $[8,9]$. Therefore, traditional screening is performed using a limited number of ovarian strips that are ultimately not transplanted. As a consequence of this approach, autotransplanting ovarian tissue involves the risk of reimplanting diseased cells that can lead to cancer relapse in some patients.

To safeguard the transfer of cortical ovarian tissue to the patient, methods must be developed in which tumor cells can be detected in ovarian autografts while preserving the tissue's reproductive function. Near-infrared fluorescence (NIRF) imaging might be a suitable approach, as this technique can safely distinguish malignant tissues from non-malignant tissues in real time while leaving the tissues viable [10]. A NIRF probe consists of a fluorophore that emits light in the near-infrared spectrum $(\lambda=700-900 \mathrm{~nm})$ conjugated to an antibody or peptide with high affinity for a protein marker expressed selectively at the cell surface of tumor cells $[11,12]$.

The first step towards developing tumor-specific imaging is the identification of protein markers that are present selectively at the cell surface of tumor cells, but absent on cells within the normal ovarian cortex. Because breast cancer is one of the primary indications for cryopreservation of ovarian tissue [13-16] and breast cancer metastases in the ovaries have been reported with a prevalence ranging from 13 to $47 \%$ [8, 17], we examined a panel of cellsurface markers known to be expressed by breast cancer cells. This panel included human epidermal growth factor receptor type 2 (Her2/neu) [18, 19], E-cadherin [20], and carcinoembryonic antigen (CEA) [21]. In addition, we tested several markers involved in tumor invasion and migration, including epithelial cell adhesion molecule (EpCAM) [22, 23], av $\beta 6$ integrin [24], urokinase-type plasminogen activator receptor (uPAR) [25, 26], and epithelial membrane antigen (EMA, also known as MUC1) $[27,28]$. Lastly, we included folate receptor-alpha (FR- $\alpha$ ), which is expressed in several tumor types but not in normal ovarian tissue [29]. We excluded cytokeratin CAM 5.2, gross cystic disease fluid protein-15 (GCDFP15), Wilms' tumor antigen-1 (WT1), mammaglobin 1, and cytokeratin 7 (CK-7), which were used previously by Sánchez-Serrano et al. [30] and Rosendahl et al. [31], as these proteins are not expressed at the cell surface and therefore not suitable as a target for tumor-specific imaging.

In this study, we measured the expression levels of the above-mentioned markers in breast cancer cells obtained from patients who were potentially eligible for cryopreservation of ovarian tissue. In addition, we compared these expression levels to expression in normal ovarian tissues.

\section{Materials and methods}

\section{Tissue specimens}

\section{Control ovaries}

Formalin-fixed, paraffin-embedded (FFPE) specimens of control ovaries obtained from premenopausal patients who underwent a unilateral or bilateral oophorectomy in 2001-2012 were selected from the archives of the Department of Pathology at the Leiden University Medical Center (LUMC). The clinical data were extracted from the patients' medical records. Indications for surgery included suspected malignancy in the contralateral ovary, earlystage uterine sarcoma, endometrial carcinoma, squamous cell carcinoma of the cervix, or enlarged ovary during pregnancy. BRCA mutation carriers and women with unknown $B R C A$ mutation status were excluded. Patients who used a gonadotropin-releasing hormone $(\mathrm{GnRH})$ agonist or oral contraceptives prior to oophorectomy were excluded to ensure that only functionally active ovaries were studied. A pathologist specialized in gynecology confirmed the absence of overt abnormalities in the ovaries by reviewing hematoxylin-and-eosin-stained sections. A total of ten control ovaries from ten different patients were included.

\section{Breast cancer tissue}

Breast tumor samples were collected from 24 patients who were potentially eligible for cryopreservation of their ovarian tissue based on the inclusion criteria established by the Dutch Network of Fertility Preservation [32]. All women were $\leq 35$ years of age and were diagnosed with invasive breast carcinoma for which they were treated surgically at the LUMC in 1997-2009. The following data were obtained from the medical records: age at the time the tissue was obtained, TNM (tumor/node/metastasis) stage, histological subtype, Scarff-Bloom-Richardson (SBR) grade, and expression of the estrogen and progesterone receptors. All patients were eligible for adjuvant chemotherapy based on the current protocols, and none was diagnosed with distant metastases.

\section{Immunohistochemistry}

Immunohistochemistry was performed on $4-\mu \mathrm{m}$ thick FFPE sections of control ovaries and $4-\mu \mathrm{m}$ thick slices of a tissue microarray (TMA) containing invasive breast tumor 
cores. To generate the TMA, tissue biopsies measuring $1.0 \mathrm{~mm}$ in diameter were taken in triplicate from representative regions of the FFPE tumor samples and arrayed into a new recipient paraffin block using TMA Master (3DHistech, Hungary). The tissue sections were deparaffinized in xylene, rehydrated in a stepwise series of graded alcohol solutions, and rinsed in distilled water. After blocking endogenous peroxidase activity with $0.3 \%$ hydrogen peroxide for $20 \mathrm{~min}$, heat-induced antigen retrieval was performed by placing the slides in EnVision Flex Target Retrieval Solution high $\mathrm{pH} /$ low $\mathrm{pH}$ in PT Link (Dako, Denmark). EpCAM and av $\beta 6$ integrin epitopes were unmasked by 30 -min incubation with $0.125 \%$ trypsin and $0.4 \%$ pepsin, respectively, at $37{ }^{\circ} \mathrm{C}$. The sections were incubated overnight in a humidified chamber at room temperature with primary antibodies against Her2/neu (ERBB2, rabbit polyclonal, Dako), E-cadherin (NCH38, mouse monoclonal, Dako), EpCAM (323/A3, mouse monoclonal, provided by the Department of Pathology, LUMC, the Netherlands), CEA (A0115, rabbit polyclonal, Dako), $\alpha v \beta 6$ integrin (6.2A1, mouse monoclonal, Cell Essentials), uPAR (ATN615, mouse monoclonal, kindly provided by Prof. A.P. Mazar, Northwestern University, Evanston, IL), or EMA (E29, mouse monoclonal, Dako); all primary antibodies were used at their predetermined optimal dilution. Some sections were incubated with an antibody against FR- $\alpha$ (26B3.F2, mouse monoclonal, Biocare Medical) for $60 \mathrm{~min}$ in accordance with the manufacturer's instructions. After incubation with the primary antibody, the sections were rinsed with PBS, incubated with secondary antibody (anti-mouse or anti-rabbit EnVision; Dako) for $30 \mathrm{~min}$, and visualized using liquid $\mathrm{DAB}+$ substrate buffer (Dako). The sections were counterstained with Mayer's hematoxylin solution, dehydrated, and permanently mounted with Pertex (Leica Microsystems, Germany). For each immunostain, a positive control expressing the antigen of interest was included. The primary antibody was omitted as a negative control.

\section{Image capture and quantification of immunoreactivity}

The immunostained slides were scanned using a Pannoramic MIDI digital slide scanner (3DHistech, Hungary). Immunohistochemical staining of the ovary sections was evaluated by the primary researcher (I.P.) and an experienced pathologist specialized in gynecology (V.S.). In each breast tumor tissue core sample, the percentage of breast tumor cells and the percentage of positively stained membranes among the malignant cells were scored by two independent observers (I.P. and R.V.). In the event of a major discrepancy, the observers reached consensus regarding a final score. The tumor cell membranes were considered positive if they showed immunoreactivity of any intensity. A weighted scoring method based on the size of the tumor area in each tumor core was used to calculate the percentage of positive membrane-stained tumor cells in each sample.

\section{Statistical analysis}

Statistical analysis was performed using SPSS version 20.0 (IBM, Armonk, NY). Inter-observer agreement was calculated using the Pearson correlation coefficient. The suitability threshold for the putative NIRF probe targets was set at 80,90 , or $100 \%$ of tumor cells expressing the antigens.

\section{Results}

\section{Control ovaries}

A histological analysis showed that all ovaries contained follicles. The cortex of each ovary was negative for immunohistochemical staining by all markers tested. In contrast, all markers (except CEA and uPAR) were detected at the plasma membrane of epithelial cells in inclusion cysts (Fig. 1a, b). These inclusion cysts were present in five of the ten ovaries. In addition, E-cadherin was expressed at moderate levels in the granulosa cells of primary follicles (Fig. 2).

\section{Breast cancer tissue}

The median age at the time of diagnosis was 32 years (range 21-35 years) for the 24 patients included in the TMA analysis. Twenty-three patients were diagnosed with ductal breast cancer, and the remaining patient was diagnosed with lobular breast carcinoma. The characteristics of these 24 patients and their tumors are summarized in Table 1.

\section{Expression of investigated markers}

Microscopic quantification of marker levels was possible in all breast tumor samples. Strong correlation was obtained between the scoring results obtained by the two observers; the median $R^{2}$ was 0.746 (range $0.626-0.818$ ). E-cadherin, EMA, Her2/neu, CEA, and uPAR staining was positive in both the plasma membrane and cytoplasm of the breast cancer cells, whereas av $\beta 6$ integrin, EpCAM, and FR- $\alpha$ staining was confined to the membrane. In addition, uPAR staining was observed in stromal cells surrounding the tumor cells (Fig. 3).

The median (range) percentage of positive tumor cells was $94 \%(5-100)$ for E-cadherin, $78 \%(13-100)$ for EMA, $61 \%(11-100)$ for Her2/neu, $56 \%$ (2-100) for 
a
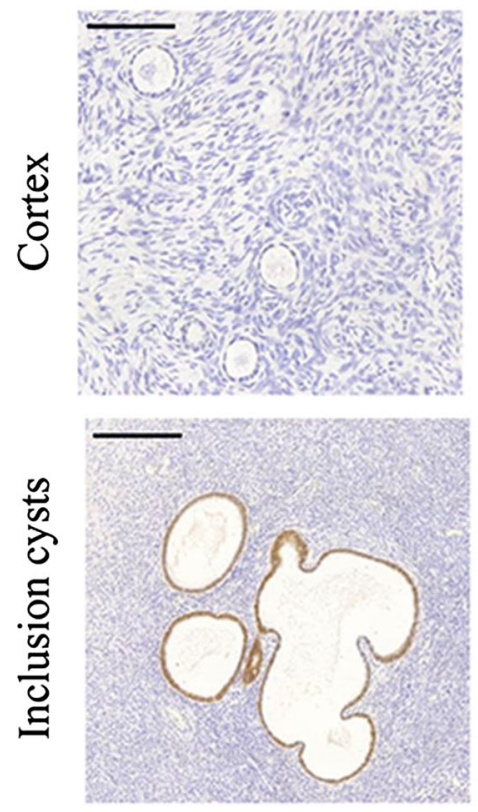

b
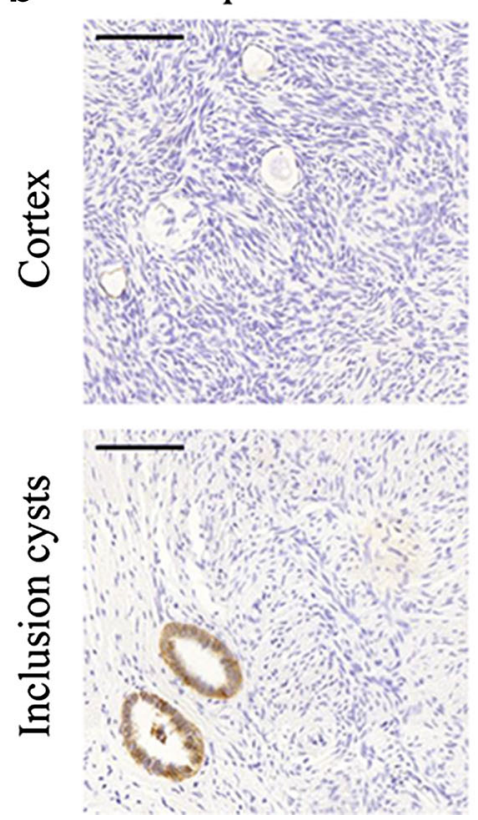

Fig. 1 a Immunohistochemical expression of E-cadherin, EMA, Her2/neu and $\alpha v \beta 6$ integrin in ovarian cortices and inclusion cysts. Stromal cells stained negative, but E-cadherin, EMA, Her2/neu and $\alpha v \beta 6$ integrin showed expression at the epithelial cells of inclusion cysts. Scale bars in the upper panel represent $100 \mu \mathrm{m}$ and scale bars in the lower panel represent $200 \mu \mathrm{m}$. b Immunohistochemical

av $\beta 6$ integrin, $54 \%(0-100)$ for EpCAM, $23 \%(0-100)$ for CEA, and $3 \%(0-100)$ for FR- $\alpha$. uPAR was expressed in extremely few tumor and stromal cells, $0 \%(0-11)$ and $0 \%(0-14)$, respectively (Table 2 ).
Her2/neu
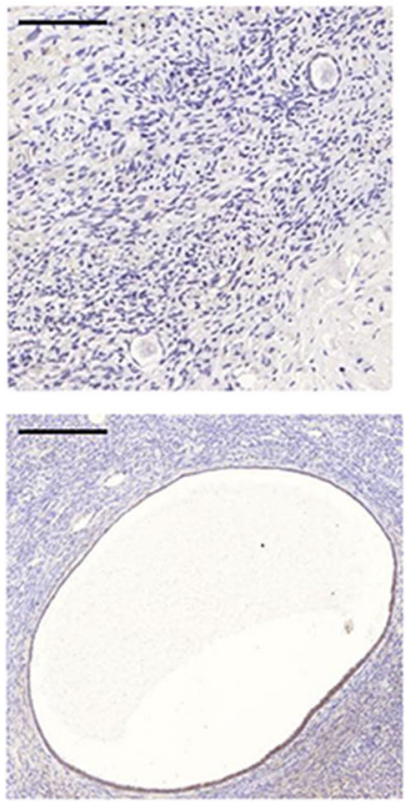

FR- $\alpha$
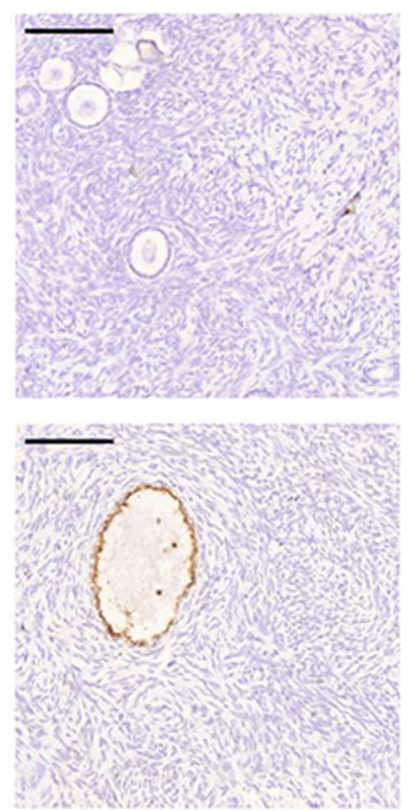

$\alpha v \beta 6$ integrin
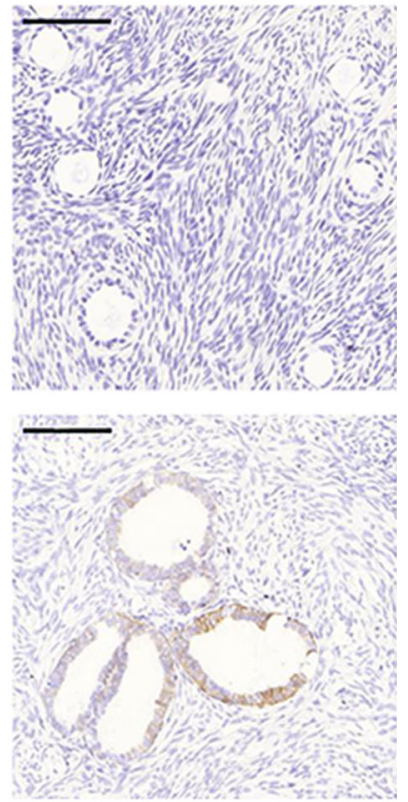

UPAR
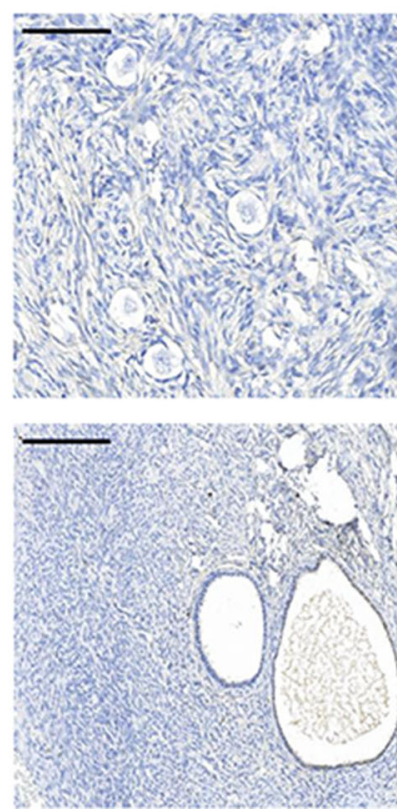

expression of EpCAM, CEA, FR- $\alpha$ and uPAR in ovarian cortices and inclusion cysts. Stromal cells stained negative, but EpCAM and FR- $\alpha$ showed expression at the epithelial cells of inclusion cysts. Scale bars in the upper panel represent $100 \mu \mathrm{m}$ and scale bars in the lower panel represent $200 \mu \mathrm{m}$

\section{Potential targets for imaging}

Given that breast cancer is relatively heterogeneous and that the expression of antigens varied among the tumors 


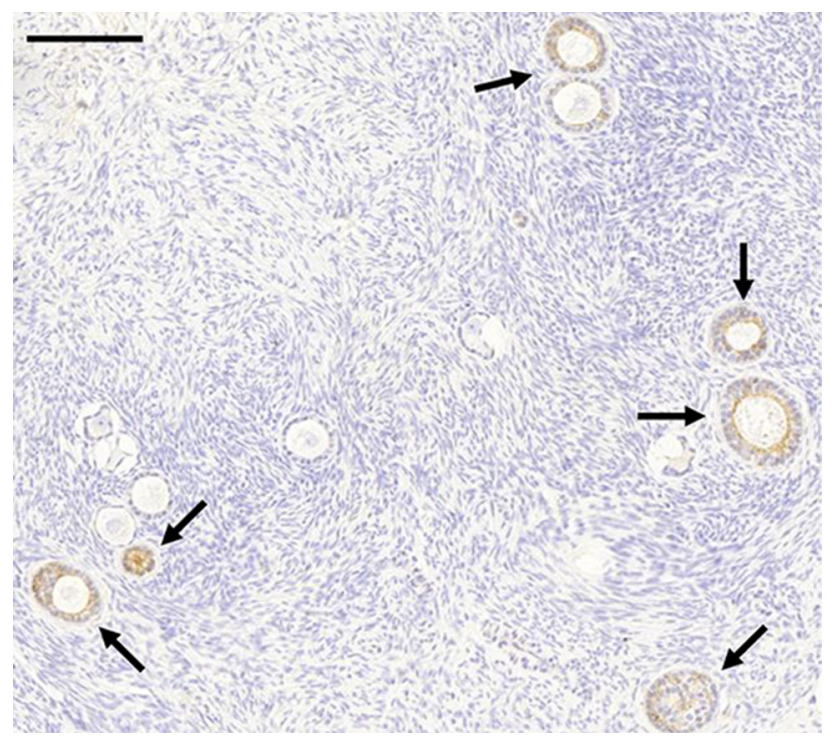

Fig. 2 Immunohistochemical staining of E-cadherin showed moderate expression in the granulosa cells of primary follicles in the ovarian cortex (arrows). Scale bar represents $200 \mu \mathrm{m}$

examined (Table 2), targeting one membrane protein would likely be insufficient for detecting all possible tumor cells in each patient. Therefore, to facilitate the selection of possible targets, we used suitability thresholds set at 80,90 , and $100 \%$, corresponding to the percentage of tumor cells that expressed the various antigens.

Figure 4 summarizes the suitability of each tumor marker for detecting invasive tumor cells in the 24 patients who were diagnosed with breast cancer. Based on this analysis, E-cadherin was identified as the most suitable marker for detecting breast cancer cells; specifically, E-cadherin was present in $100 \%$ of cells in five tumors, and this marker was present in $\geq 90 \%$ of cells in 17 tumors. The seven tumors with $<90 \%$ positivity for E-cadherin were positive for the markers EMA (1 tumor; $100 \%$ of cells detected), $\alpha v \beta 6$ integrin (3 tumors; 78-93\% of cells detected), EpCAM (1 tumor; $81 \%$ of cells detected), E-cadherin (1 tumor; $80 \%$ of cells detected), and Her2neu (1 tumor; $76 \%$ of cells detected). Two tumors had $<80 \%$ positivity for all of the markers tested (Table 2). In these two tumors, 76 and $78 \%$ of the tumor cells were detected by the markers, corresponding to a maximum of 24 and $22 \%$ of undetected malignant cells, respectively.

\section{Comment}

Here, we identified several proteins that could potentially serve as a suitable target for detecting breast cancer cells within ovarian autografts. One clear application for these
Table 1 Clinicopathologic characteristics in premenopausal patients with primary invasive breast cancer

\begin{tabular}{ll}
\hline Characteristic & $N=24$ \\
\hline Age at diagnosis, years-median (range) & $32.0(21-35)$ \\
Tumor size, mm-median (range) & $20.5(10-45)$ \\
Tumor stage, no. (\%) & \\
pT1 & $11(45.8)$ \\
pT2 & $12(50.0)$ \\
pT3 & $1(4.2)$ \\
pT4 & $0(0.0)$ \\
Lymph node involvement, no. (\%) & \\
pN0 & $13(54.2)$ \\
pN1 & $11(45.8)$ \\
Scarff-Bloom-Richardson grade, no. (\%) & \\
I & $2(8.3)$ \\
II & $9(37.5)$ \\
III & $13(54.2)$ \\
Histological subtype, no. (\%) & \\
Ductal & $23(95.8)$ \\
Lobular & $1(4.2)$ \\
Estrogen receptor, no. (\%) & \\
Negative & $12(50.0)$ \\
Positive & $9(37.5)$ \\
Unknown & $3(12.5)$ \\
Progesterone receptor, no. (\%) & \\
Negative & $15(62.5)$ \\
Positive & $6(25.0)$ \\
Unknown & $3(12.5)$ \\
\hline
\end{tabular}

markers is the use of NIRF imaging, a technique that can differentiate malignant tissues from non-malignant tissues without reducing the tissue's viability [10, 33-35]. Designing a NIRF probe directed against E-cadherin shows particular promise, as E-cadherin was expressed by the majority (94\%) of invasive breast tumor cells and was absent on the surface of normal ovarian cells. However, a combination of tumor-selective probes will likely be needed to detect all tumor cells. Based on our results, a combination of probes against E-cadherin, EMA and Her2/ neu seems suitable.

Metastatic spread requires the local invasion of the surrounding host tissue by cells that originated from the primary tumor, followed by intravasation in blood and lymphatic vessels, ultimately leading to the dissemination of tumor cells [36]. E-cadherin and EpCAM mediate cellcell adhesion, and the downregulation or loss-of-function of these proteins enables cells to escape from solid tumors [19]. E-cadherin and/or EpCAM are not necessarily expressed in all tumor cells; therefore, metastatic tumor cells might not be detected in some tissues. Furthermore, the majority of metastatic lobular breast cancer cells, which 
E-cadherin

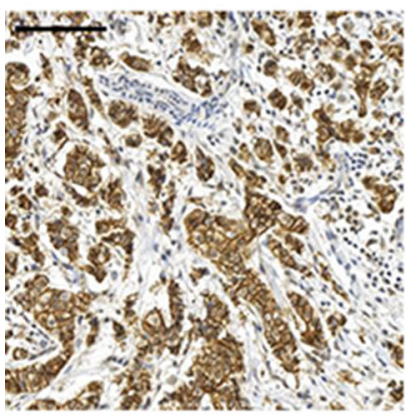

EpCAM

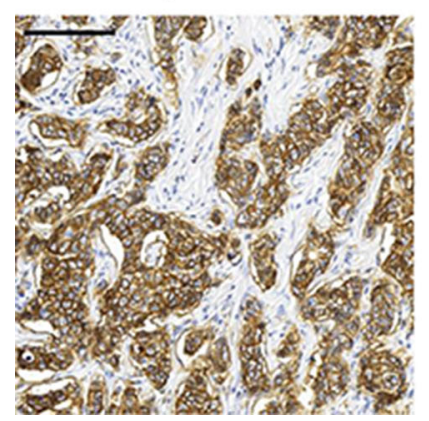

EMA

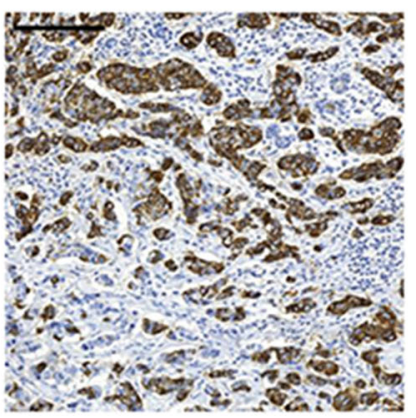

CEA

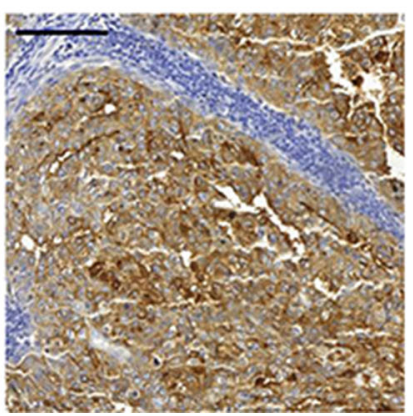

Her2/neu

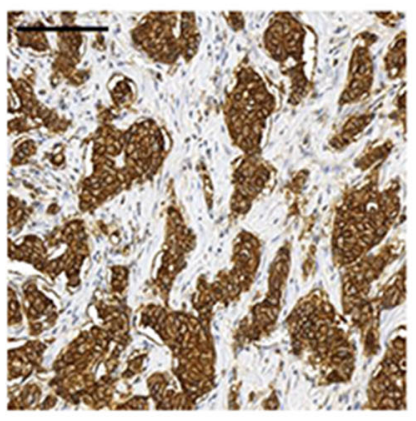

FR- $\alpha$

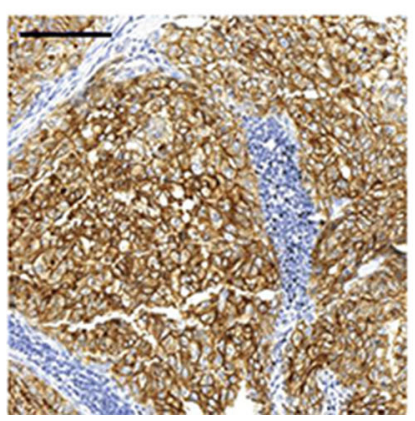

$\alpha v \beta 6$ integrin

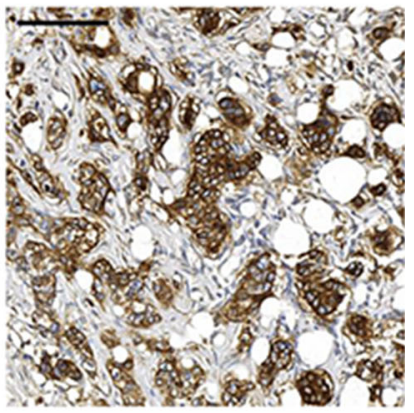

UPAR

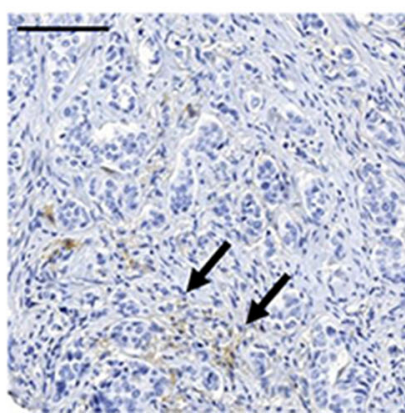

Fig. 3 Immunohistochemical expression of E-cadherin, EMA, Her2/neu, $\alpha$ v $\beta 6$ integrin, EpCAM, CEA, FR- $\alpha$ and uPAR in invasive breast cancer. uPAR was barely expressed in stromal cells surrounding the tumor (arrows). Scale bars represent $100 \mu \mathrm{m}$

Table 2 The percentage of tumor cells in each tumor showing positive expression for the investigated tumor markers

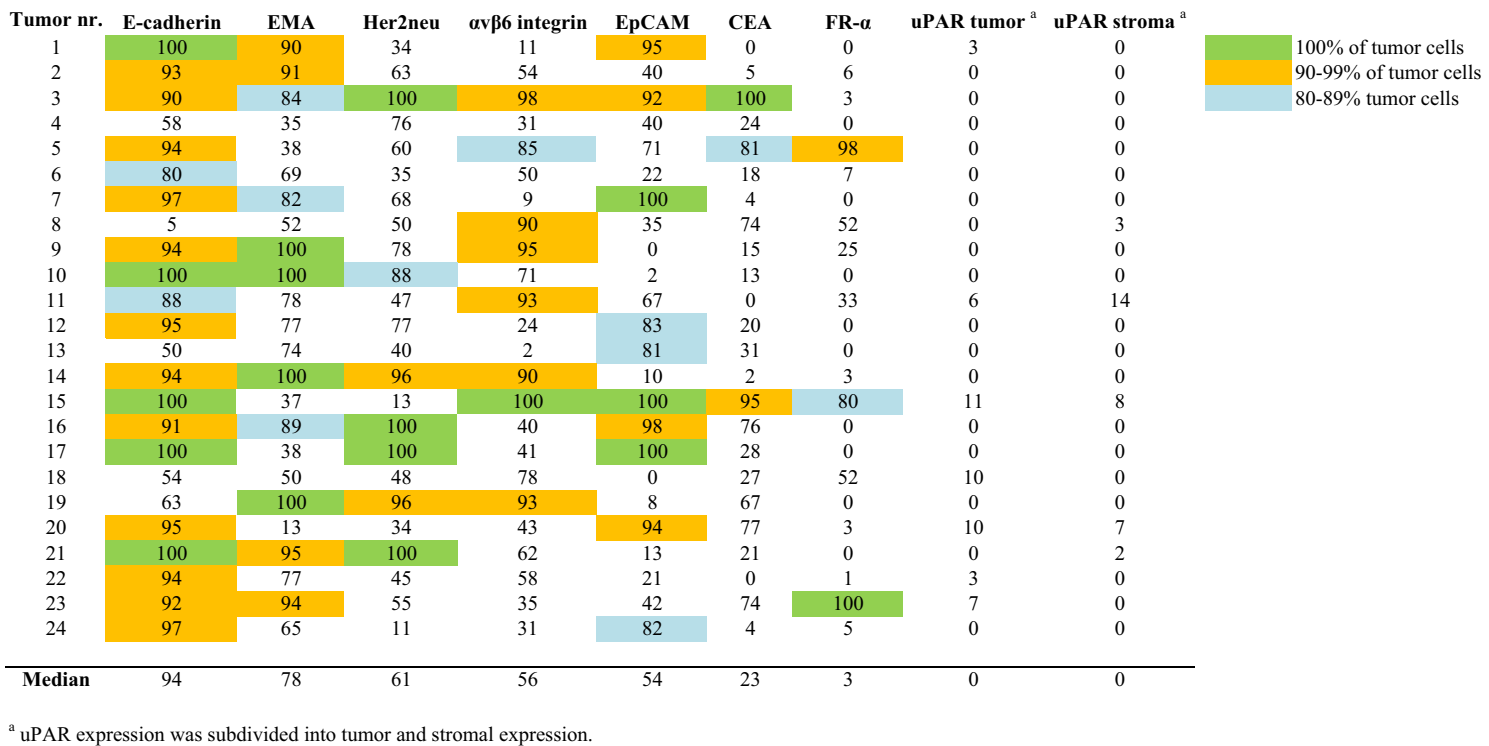

lack E-cadherin expression, will not be detected using a specific anti-E-cadherin probe, even though lobular breast cancer cells are more likely to invade ovarian tissue compared to cells derived from ductal carcinomas [37, 38].
As mentioned above, we considered tumor cell membranes positive if they showed immunoreactivity of any intensity. As a result, some tumor cells might be more positive than others for the investigated markers. Yet, for 


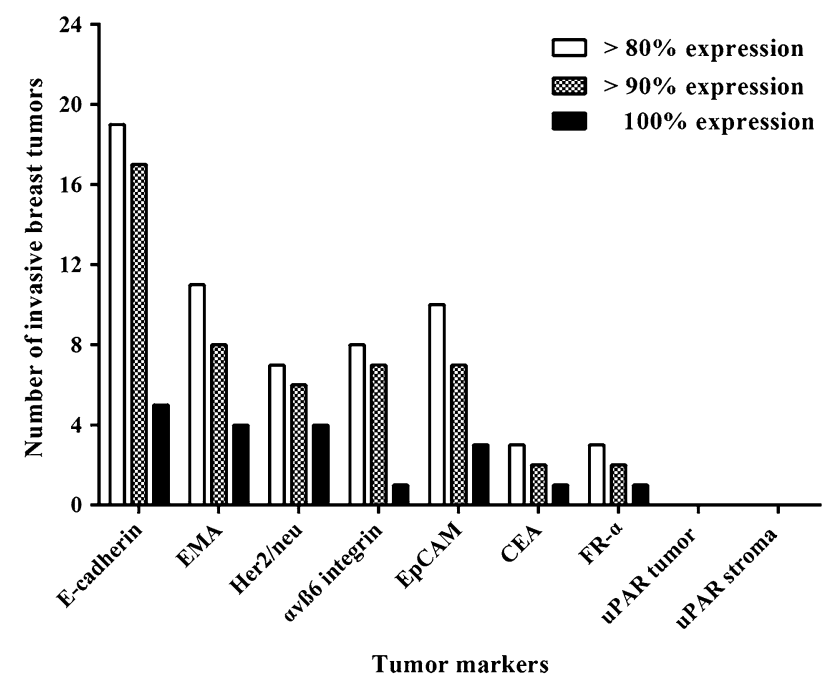

Fig. 4 Suitability of tumor markers to use as a target for the detection of tumor cells in premenopausal women with invasive breast cancer $(n=24)$. Columns represent the number of tumors in which at least 80 , at least 90 or $100 \%$ of the tumor cells showed expression of the tumor markers. For uPAR, stromal cell expression is also shown

NIRF imaging, the staining intensity is less important as long as a significant tumor-to-background-ratio can be achieved.

None of the premenopausal ovaries in our cohort had positive staining in either the stromal cells or the ovarian surface epithelium. However, all markers (except CEA and uPAR) were expressed on epithelial cells in inclusion cysts. Consequently, conjugating antibodies against these markers to a NIR fluorophore will illuminate invasive breast cancer cells in the ovary, as well as inclusion cysts. Because inclusion cysts might differ from metastatic breast cancer cells with respect to their fluorescent configuration, it might be possible to distinguish between these structures. The same strategy might be used to distinguish granulosa cells in primary follicles from metastatic breast cancer cells that express E-cadherin. In addition, full-field optical coherence tomography (FF-OCT), a non-invasive imaging technique that mimics conventional histopathology, might be very useful. In the field of dermatological oncology, FFOCT has already been proven capable of visualizing sebaceous glands and adipose tissue surrounding hair follicles as well as small malignant skin tumors [39]. On high magnification, fine architectural details on the subcellular level can be recognized. Therefore, it is expected that FFOCT will also be able to distinguish inclusion cysts from metastatic tumor cells in ovarian tissue.

One strength of our study is that we examined the expression of tumor markers in tumor tissues obtained from young breast cancer patients who met the criteria for ovarian tissue cryopreservation. Moreover, only biologically active ovaries were analyzed, giving the results clinical relevance, as ovarian tissue is generally cryopreserved before ovarian failure has occurred.

On the other hand, this study has some limitations that merit discussion. First, a relatively small sample size was examined. However, normal ovarian tissue from premenopausal patients is not readily available. We excluded ovaries that were removed due to the presence of a $B R C A$ gene mutation, as such samples could contain primary ovarian tumor cells [40], that express the markers investigated in this study. To be certain, we also excluded ovaries from breast cancer patients with unknown mutation status. At the LUMC, normal ovarian tissue from premenopausal breast cancer patients was exclusively available from $B R C A$ mutation carriers or women with unknown mutation status. As a consequence, ovaries from breast cancer patients were not included in this study. Malignant cells may also be present in ovaries that were removed due to endometrial carcinoma, uterine sarcoma, cervical squamous cell carcinoma, or contralateral ovarian carcinoma; however, the risk of false-positive results was relatively low in our cohort, as all primary tumors were diagnosed at an early stage and the lymph nodes in these patients were clear. Second, the expression of the markers was evaluated on primary invasive breast tumors, since a substantial cohort consisting of ovarian tissues containing breast cancer metastases is scarce. Finally, we examined the expression of tumor markers in relatively small tumor cores using a TMA approach. Yet, the TMA technique is considered an accurate method for examining protein expression in breast cancer tissues [41].

Recently, the intraoperative use of tumor-targeted fluorescent imaging yielded a high tumor identification rate and enabled the surgeon to detect metastases that could not be detected by visual observation [42]. For our purpose, tumor-specific NIRF probes could be administered intravenously prior to oophorectomy, after which the removed ovary is dissected into cortical ovarian strips. Detailed fluorescent images could then be obtained using multiphoton microscopy, which provides an inherent submicron spatial resolution that allows revelation of subcellular details with reduced phototoxicity and photobleaching [43, 44]. Because the NIRF signal lies beyond the red end of the visible spectrum, the signal has enhanced tissue penetration, enabling the identification of fluorescently labeled tumor cells that are located deep within the tissue. Moreover, the low autofluorescence of the tissue at the emission wavelength of the probe provides a high tumor-to-background ratio [45]. Because of these features and the fact that cortical ovarian fragments can be imaged from both the upper and lower side, thereby increasing the imaging depth even further, NIRF imaging is a promising technique for detecting tumor cells in cortical ovarian strips up to $2 \mathrm{~mm}$ in thickness. 
In conclusion, we report the identification of tumor markers that may serve as a target for detecting breast cancer cells in ovarian tissue using robust imaging techniques such as NIRF imaging. Based on our analysis, E-cadherin is likely the most suitable target for designing a tumor-specific probe. Further research will focus on examining the expression of these markers on breast cancer metastases in ovaries, refining methods to distinguish breast cancer cells from ovarian inclusion cysts, and examining the clinical feasibility of applying NIRF imaging to the field of fertility preservation.

Acknowledgments The authors thank N. Geeske Dekker-Ensink, MSc, and Ronald L.P. van Vlierberghe, BSc for practical help. This work was supported by the project grant H2020-MSCA-RISE grant number 644373 - PRISAR, DSW Health Insurance, and the Zabawas Foundation. These funding sources were not involved in any part of the study.

\section{Compliance with ethical standards}

Ethics approval All patient samples and clinical data were handled in accordance with the medical ethics guidelines described in the Code of Conduct for Proper Secondary Use of Human Tissue of the Dutch Federation of Biomedical Scientific Societies (FMWV) [46].

Conflict of interest The authors declare that they have no conflict of interest. Authors have full control of all primary data. They agree to allow the journal to review the data if requested.

Open Access This article is distributed under the terms of the Creative Commons Attribution 4.0 International License (http://crea tivecommons.org/licenses/by/4.0/), which permits unrestricted use, distribution, and reproduction in any medium, provided you give appropriate credit to the original author(s) and the source, provide a link to the Creative Commons license, and indicate if changes were made.

\section{References}

1. Blumenfeld Z (2012) Chemotherapy and fertility. Best Pract Res Clin Obstet Gynaecol 26(3):379-390

2. Loscalzo MJ (2007) The psychosocial context of cancer-related infertility. Cancer Treat Res 138:180-190

3. Jeruss JS, Woodruff TK (2009) Preservation of fertility in patients with cancer. N Engl J Med 360:902-911

4. Rodriguez-Wallberg KA, Oktay K (2012) Recent advances in oocyte and ovarian tissue cryopreservation and transplantation. Best Pract Res Clin Obstet Gynaecol. 26(3):391-405

5. Von Wolff M, Montag M, Dittrich R, Denschlag D, Nawroth F, Lawrenz B (2011) Fertility preservation in women-a practical guide to preservation techniques and therapeutic strategies in breast cancer, Hodgkin's lymphoma and borderline ovarian tumours by the fertility preservation network FertiPROTEKT. Arch Gynecol Obstet 284:427-435

6. Donnez J, Dolmans M-M, Pellicer A et al (2013) Restoration of ovarian activity and pregnancy after transplantation of cryopreserved ovarian tissue: a review of 60 cases of reimplantation. Fertil Steril 99(6):1503-1513

7. Stoop D, Cobo A, Silber S (2014) Fertility preservation for agerelated fertility decline. Lancet 384(9950):1311-1319
8. Bastings L, Beerendonk CCM, Westphal JR et al (2013) Autotransplantation of cryopreserved ovarian tissue in cancer survivors and the risk of reintroducing malignancy: a systematic review. Hum Reprod Update, pp 1-24

9. Bastings L, Beerendonk CCM, Westphal JR, Braat DDM, Peek R (2013) Cryopreservation and autotransplantation of ovarian tissue in cancer patients: is it safe? J Adolesc Young Adult Oncol 2(1):31-34

10. Vahrmeijer AL, Hutteman M, Van Der Vorst JR, Van De Velde CJ, Frangioni JV (2013) Image-guided cancer surgery using nearinfrared fluorescence. Nat Rev Clin Oncol. 10(9):507-518

11. Keereweer S, Kerrebijn JDF, Van Driel PBAA et al (2011) Optical image-guided surgery-where do we stand? Mol Imaging Biol 13(2): 199-207

12. Te Velde EA, Veerman T, Subramaniam V, Ruers T (2010) The use of fluorescent dyes and probes in surgical oncology. Eur $\mathrm{J}$ Surg Oncol 36(1):6-15

13. Rosendahl M, Schmidt KT, Ernst E et al (2011) Cryopreservation of ovarian tissue for a decade in Denmark: a view of the technique. Reprod Biomed Online 22(2):162-171

14. Dolmans M-M, Jadoul P, Gilliaux S et al (2013) A review of 15 years of ovarian tissue bank activities. J Assist Reprod Genet 30(3):305-314

15. Oktay K, Oktem O (2010) Ovarian cryopreservation and transplantation for fertility preservation for medical indications: report of an ongoing experience. Fertil Steril 93(3):762-768

16. Hoekman EJ, Smit VT, Fleming TP, Louwe LA, Fleuren GJ, Hilders CG (2014) Searching for metastases in ovarian tissue before autotransplantation: a tailor-made approach. Fertil Steril 103(2):469-477

17. Perrotin F, Marret H, Bouquin R, Lansac J, Body G (2001) Incidence, diagnostic et pronostic des métastases ovariennes du cancer du sein. Gynécol Obstét Fertil 29:308-315

18. Slamon DJ, Clark GM, Wong SG, Levin WJ, Ullrich A, Mcguire WL (1987) Human breast cancer: correlation of relapse and survival with amplification of the HER-2/neu oncogene. Science 235:177-182

19. Weigelt B, Peterse JL, van 't Veer LJ (2005) Breast cancer metastasis: markers and models. Nat Rev Cancer 5(8):591-602

20. Cowin P, Rowlands TM, Hatsell SJ (2005) Cadherins and catenins in breast cancer. Curr Opin Cell Biol 17(5):499-508

21. Kuhajda FP, Offutt LE, Mendelsohn G (1983) The distribution of carcinoembryonic antigen in breast carcinoma. Diagnostic and prognostic implications. Cancer 52(7):1257-1264

22. Schnell U, Cirulli V, Giepmans BNG (2013) EpCAM: structure and function in health and disease. Biochim Biophys Acta 1828(8):1989-2001

23. Soysal SD, Muenst S, Barbie T et al (2013) EpCAM expression varies significantly and is differentially associated with prognosis in the luminal B HER2 $(+)$, basal-like, and HER2 intrinsic subtypes of breast cancer. $\mathrm{Br} \mathrm{J}$ Cancer 108(7): 1480-1487

24. Rathinam R, Alahari SK (2010) Important role of integrins in the cancer biology. Cancer Metastasis Rev 29(1):223-237

25. Boonstra MC, Verspaget HW, Ganesh S et al (2011) Clinical applications of the urokinase receptor (UPAR) for cancer patients. Curr Pharm Des 17(19):1890-1910

26. Tang L, Han X (2013) The urokinase plasminogen activator system in breast cancer invasion and metastasis. Biomed Pharmacother 67(2):179-182

27. Tornos C, Soslow R, Chen S et al (2005) Expression of WT1, CA 125 and GCFFP-15 as useful markers in the differential diagnosis of primary ovarian carcinomas versus metastatic breast cancer to the ovary. Am J Surg Pathol 29:1482-1489

28. Luyckx V, Durant JF, Camboni A et al (2013) Is transplantation of cryopreserved ovarian tissue from patients with advanced- 
stage breast cancer safe? A pilot study. J Assist Reprod Genet 30(10):1289-1299

29. Markert S, Lassmann S, Gabriel B et al (2008) Alpha-folate receptor expression in epithelial ovarian carcinoma and nonneoplastic ovarian tissue. Anticancer Res 28:3567-3572

30. Sánchez-Serrano M, Novella-Maestre E, Roselló-Sastre E, Camarasa N, Teruel J, Pellicer A (2009) Malignant cells are not found in ovarian cortex from breast cancer patients undergoing ovarian cortex cryopreservation. Hum Reprod 24(9):2238-2243

31. Rosendahl M, Timmermans Wielenga V, Nedergaard L et al (2011) Cryopreservation of ovarian tissue for fertility preservation: no evidence of malignant cell contamination in ovarian tissue from patients with breast cancer. Fertil Steril 95(6):2158-2161

32. Nederlands Netwerk Fertiliteitspreservatie (NNF; Dutch Network of Fertility Preservation) (2012) Landelijk protocol cryopreservatie en transplantatie van ovariumweefsel. http://nnf-info.nl. Updated September 2012

33. Schaafsma BE, Mieog JSD, Hutteman M et al (2011) The clinical use of indocyanine green as a near-infrared fluorescent contrast agent for image-guided oncologic surgery. J Surg Oncol 104(3):323-332

34. Hutteman M, Van Der Vorst JR, Mieog JSD et al (2011) Nearinfrared fluorescence imaging in patients undergoing pancreaticoduodenectomy. Eur Surg Res 47(2):90-97

35. Van Der Vorst JR, Schaafsma BE, Hutteman M et al (2013) Nearinfrared fluorescence-guided resection of colorectal liver metastases. Cancer 119(18):3411-3418

36. Scully OJ, Bay B-H, Yip G, Yu Y (2012) Breast cancer metastasis. Cancer Genomics Proteomics 9:311-320

37. Mccluggage WG, Wilkinson N (2005) Metastatic neoplasms involving the ovary: a review with an emphasis on morphological and immunohistochemical features. Histopathology 47(3):231-247
38. Dolmans M-M, Luyckx V, Donnez J, Andersen CY, Greve T (2013) Risk of transferring malignant cells with transplanted frozen-thawed ovarian tissue. Fertil Steril 99(6):1514-1522

39. Durkin JR, Fine JL, Sam H, Pugliano-Mauro M, Ho J (2014) Imaging of Mohs micrographic surgery sections using full-field optical coherence tomography: a pilot study. Dermatol Surg 40(3):266-274

40. Rhiem K, Foth D, Wappenschmidt B, Gevensleben H, Büttner R, Ulrich U, Schmutzler RK (2011) Risk-reducing salpingooophorectomy in BRCA1 and BRCA2 mutation carriers. Arch Gynecol Obstet 283:623-627

41. Kotzsch M, Bernt K, Friedrich K et al (2010) Prognostic relevance of tumour cell-associated UPAR expression in invasive ductal breast carcinoma. Histopathology 57(3):461-471

42. Van Dam GM, Themelis G, Crane LMA et al (2011) Intraoperative tumor-specific fluorescence imaging in ovarian cancer by folate receptor- $\alpha$ targeting: first in-human results. Nat Med 17(10):1315-1319

43. Andresen V, Alexander S, Heupel W-M, Hirschberg M, Hoffman RM, Friedl P (2009) Infrared multiphoton microscopy: subcellularresolved deep tissue imaging. Curr Opin Biotechnol 20(1):54-62

44. Cahalan MD, Parker I, Wei SH, Miller MJ (2002) Two-photon tissue imaging: seeing the immune system in a fresh light. Nat Rev Immunol 2(11):872-880

45. Themelis G, Harlaar NJ, Kelder W et al (2011) Enhancing surgical vision by using real-time imaging of $\alpha \mathrm{v} \beta 3$-integrin targeted nearinfrared fluorescent agent. Ann Surg Oncol 18(12):3506-3513

46. Federa FMWV. Code for proper secondary use of human tissue in the Netherlands 2002. http://www.federa.org/codes-conduct 